\title{
Minimization of Transportation Cost in Dairy Industry
}

\author{
Thirupathi Raj $\mathrm{K}^{\mathrm{A}^{*}}$, Arunmozhi $\mathrm{B}^{\mathrm{B}^{*}}$,Dr.Sivasankaran $\mathrm{R}^{\mathrm{C}^{*}}$ \\ A* ${ }^{*}$ G-Scholar, Department of Mechanical Engineering, Thiagarajar College of Engineering Madurai, India \\ B* PG-Scholar, Department of Mechanical Engineering, Thiagarajar College of Engineering Madurai, India \\ C* Assistant Professor, Department of Mechanical Engineering, Thiagarajar College of Engineering Madurai, India
}

\begin{abstract}
A supply chain consists of organizations, people, resources and information involved in moving a product or service from supplier to customer. Risk and uncertainty have been found to be one of the indispensable parts of any manufacturing or food supply chain, No matter how strong is the supply chain, risk and uncertainty come into the picture by disrupting the operational flow. The situation further gets complicated, if the nature of the material the supply chain deals in, is perishable requiring conditioned transportation and storage. Transportation is the major function of a supply chain, which provides the movement of goods. Finding out efficient vehicle routes is an important problem. Hence transportation is a major issue in the food supply chain. In this work, the optimization of the transportation route for a public sector milk dairy in Madurai is carried out. In this firm, vehicles collect milk from various procurement points and finally reached the depot. When the firm can abbreviate the corresponding routing distance, then it will be able to provide better service and also the transportation costs can be reduced, as cost reduction is the important objective of every industry. This project also aims in a comparative study of the current transportation route used in this milk dairy and the optimized route suggested by this work considering the distance, cost, quantity, number of vehicles $\&$ road conditions.
\end{abstract}

Keywords - Food supply chain, optimization, transportation, road conditions

\section{INTRODUCTION}

The dairy industry procures milk, processes it and sells milk and milk products to consumers. The Dairy Development Department was established in Tamil Nadu, to oversee and regulate milk production and commercial distribution in the state. The Dairy Development Department took over control of the milk cooperatives. Tamil Nadu is one of the leading states in India in milk production with about 14.5 million liters per day. Formation of Village level Coop Societies. Convincing the Farmers to pour milk to Co-operative to fetch higher price. Year round Milk collection from the societies' door step by milk collection routes. Educating the farmers on Animal management, infertility and feeding management. Maintaining the book of accounts at the society level. The procurement price is calculated and given to the farmers based on the chemical quality of milk i.e. Fat and Solid Non Fat. Payments to the producers are effected once in 10 days by the Union. There are 715 functioning MPCS in Madurai. The entire economic, social and political life of a modern country depends upon efficient system of transport. Transport plays an importance role in
- Number of trucks used for collecting raw milk: 19 trucks

- Number of routes for collecting raw milk: 19.

\section{LITERATURE REVIEW}

(Jenson Joseph E, Clement Tom Scaria 2014), stated that transportation is a major issue in food supply chain. They optimized the transportation route by considering minimum distance. As the total distance is reduced, the total expense of transportation in each route is also reduced. (David Goulding, Sean O'Callaghan Declon o cooner 2018), focuses on the development of an optimal routing plan for a designated fleet of articulated lorries (trucks) and purpose-built tankers used in the collection, transportation and varying seasonal delivery patterns of milk from farms to processors over a national road network. One of the major findings of the research presented, is that because of the seasonal supply of milk the monthly variation in truck load numbers and routes are striking, suggesting that at a minimum, routes are been revised monthly rather, where for example 9 trucks could be replaced by 3 or 4. (M. Subburaj, T. Ramesh Babu, B. Suresh Subramonian), state the issues in improving the operational efficiency of the dairy supply chain in Tamil Nadu. Dairy Farming is a major occupation of the people in $\mathrm{TN}$ and it contributes a significant amount to the growth of our country. In this paper, Tamil Nadu dairy development department's objectives and its three-tier structure were studied. The dairy farmer's issues were observed through data collection and analyzed through SWOT analysis its strengths, weaknesses, opportunities and threats. Based on the research outcome some key recommendations were presented to improve the operational efficiency of dairy supply chain in Tamil Nadu, India (Alberto) deal with the shortest path to the destination by taking the traffic conditions in account. This allows the drivers to take the shortest path for avoiding traffic jams. The paper proposed an algorithm for calculating all pair of the shortest path. A parallel version of the algorithm was used to solve the pair of shortest path problem for metropolitan areas with large road networks. To make the proposed system as cost effective, shortest path calculation was needed. The algorithms like All Pair Shortest Path (APSP) and Single Source Shortest path (SSSP) provides the good performance time. It also solved the problem of identifying the alternative path (Harisri.M.Thulasi, A.K). Agrawal and S.K. Sharma) minimize the procurement cost by minimizing the distance travelled by vehicles and hence minimizing the transportation cost and 
thereby increase the profit of the plant. The Heterogeneous Fleet Vehicle Routing Problem with Time Window (HFVRPTW) and p-center were run with test data taken from a dairy industry. The p-center problem was done for 24 nodes and the results were better than in the case of current working model used in the dairy. Also by optimizing the vehicle transportation, reduced the pollution by minimizing the usage of fuel. (karthikeyan and Elango) states that Transportation cost is one of the major costs incurred during operations in courier service industry. Their profit margin depends purely on transportation cost hence they always strive to keep the cost at lower level. Hence, this paper concentrates to reduce the transportation cost by reducing the travelling distance and utilizing the maximum capacity of the vehicle. Using the reduced number of vehicles. (Ribas, Anand Subramanian, Igor Machado Coelho a , Luiz Satoru ochi , Marcone Jamilson Freitas Souza) discussed the Vehicle Routing Problem with Time Windows as a particular case of the classical Vehicle Routing Problem in which the demands of each customer should be met within an established time window. The proposed algorithm (IILS-SP) combines the metaheuristic Iterated Local Search, the Variable Neighborhood Descent procedure and an exact Set Partitioning model that, periodically, finds the best combination of the routes generated along the algorithm. Given the combinational nature of the problem, its resolution using pure exact approaches is, in many cases, computationally impractical. (Pramod Kumar Mishra, B. Raja Shekhar) addressed Risk and uncertainty have been found to be one of the indispensable parts of any manufacturing or service supply chain. The situation further gets complicated, if the nature of the material the supply chain deals in, is perishable requiring conditioned transportation and storage. The empirical paper describes the risks and uncertainties of a dairy-food supply chain case in India. The risks and uncertainties obstruct the flow of the supply chain and decrease the performance above all. The high risks are the crucial ones and need to be addressed on priority basis while medium and low risks should not be neglected at the same time. Depending upon the risk mechanism of an organization and the intensity of the risks, they could be avoided, shared, transferred, minimized or mitigated with suitable strategies. These results can be verified further in other countries to enrich the emerging concept of supply chain risks. (Roberto Baldacci, Aristide Mingozzi, Roberto Roberti) provides a review of the recent developments that had a major impact on the current state-of the-art exact algorithms for the vehicle routing problem (VRP). The paper reviews mathematical formulations, relaxations and recent exact methods for two of the most important variants of the VRP: the capacitated VRP (CVRP) and the VRP with time windows (VRPTW). This approach has significantly improved the quality of the lower bounds that are now very close to the optimal solution values. Furthermore, set partitioning based approaches proved quite general as they are easily able to incorporate additional constraints arising in practical applications. (Xiaohua) discussed the problem of shortest path. In this paper, how to refresh a cache when one edge of the underlying road network changes. Algorithm were proposed to detect the shortest path which were affected by change of the edges. The performance of the proposed strategy shows the replacement of the affected path with the new path. A bit map cache structure was used for storing the shortest path and answering the queries.
Also deals with the location based system which was useful for mobile users to suggest the shortest path. It not only suggest the current shortest path but also displays the alternate path for avoiding the traffic jams. The proposed system shows the set of algorithms which shows Al Pairs of Shortest Path in free flow and congested traffic flows. Also enabling the location based system which deals with the emergencies and critical traffic conditions. A Parallel Version of the algorithm was also proposed to solve the All Pair of Shortest Path Problem for Metropolitan areas with large roads network. (Dang Vu Tung., 1999) illustrate the operations research techniques used in waste collection activities in Hanoi, Vietnam. Methodology of mixed integer program and propose a heuristic procedure consisting of construction and improvement phase. Using the heuristic show the good performance in terms of the solution quality and computational policy from the fixed routing to the flexible can reduce operating cost and improve vehicle operation smooth coordination between vehicle and worker. (ing quanli., 2008) describe the truck scheduling in this city of alegre, Brazil. This problem is designing good daily truck schedules over a set of previously defined collective trips, minimizes the total operating and fixed costs using the methodology of Single depot scheduling, auction algorithm. The first dual heuristic is based on the q-route relaxation of the set partitioning formulation of the CVRP. The second one combines LaGrange and relaxation, pricing and cut generation. Concluded using above methodology increase the system performance in comparison of manual planning. The main idea is to adjust the auction algorithm to solve some dynamic scheduling problems, and then mainly when a severe disruption happens in the midst of operations. (Madsen) The remarkable advances in telecommunications and information technology have enabled companies to focus on velocity and timeliness throughout the supply chain. The Dynamic Vehicle Routing Problem (DVRP) is used At both ends of their supply chain, their objective is to pick-up and deliver all letters and packages within the given time restrictions while keeping the operating costs as low as possible. The cost of lateness is very high since it results in full customer reimbursement or lost sales.

\section{PROBLEM FORMULATION}

Transportation cost is one of the major costs incurred during operations in dairy industry. Their profit margin depends purely on transportation cost hence they always strive to keep the cost at lower level. Consider the dairy industry which have 210 procurement point with an aid of 19 vehicles, each vehicle has its own capacity in terms of number .of cans carried. Dairy industry wants to utilize the maximum capacity of the vehicle. While delivering and picking up the cans to/from the points, and to reduce total distance travelled while completing the shift which increases the total transportation cost. Hence, this project work concentrates to reduce the transportation cost by reducing the travelling distance and utilizing the maximum capacity of the vehicle.

The main objective of this research is minimize the procurement transportation cost by reducing the travelling distance and utilizing the maximum capacity of the vehicle.

Mathematical Modelling 


$$
F=\operatorname{Min} \sum_{i=1}^{n} \sum_{j=1}^{n} d_{i j} x_{i j}
$$

Subjected to...

$$
\begin{gathered}
\sum_{i=1}^{n} x_{i j}=1 ; j=1, \ldots, n \\
\sum_{i=1}^{n} x_{i j}-\sum_{i=1}^{n} x_{j i}=0 \quad \text { for all } j=1, \ldots, n, \\
\sum_{i=1}^{n} P_{i} x_{i j} \leq C_{V} \quad \text { for all } j=1, \ldots, n
\end{gathered}
$$

- $\mathrm{n}$ - Number of procurement points

- dij-Shortest distance between procurement point $\mathrm{i}$ and $\mathrm{j}$

- $\mathrm{Xij}=$

1 , if salesman travelling from village $i$ to village $j$

0 , if salesman is not travelling from village $i$ to village $j$

- $\mathrm{Pi}=$ quantity of cans pickup when departing from point $\mathrm{i}$

- $\mathrm{Cv}$ - Actual capacity of the vehicle

The objective function Equation 3.1 minimize the travelling distance between the procurement points of vehicle. Equation 3.2 shows that each procurement point should be visited exactly once by vehicle, Equation 3.3 is route continuity equation. Equation 3.4 shows that quantity of pickup load at procurement point should not exceed the vehicle capacity.

\section{METHODOLOGY}

The adopted methodology to address this issue to reduce the transportation cost is by clustering the pickup points on the basis of distance travelled to serve all the procurement points at minimum cost and also effectively reduce the number of transportation vehicles required. Routing of vehicle, Traveling Salesman Problem (TSP) is the simplest case where the nodes have no precedence relationship, travel costs between two nodes are the same regardless of the direction traveled; The objective is to find the shortest possible route that visits each city exactly once and returns to the origin city. Vehicle Routing Problem (VRP) is a MTSP with capacity restriction of the multiple vehicles coupled with varying demands at each node. VRP was proposed by Dantzig and Ramser in 1959. It is an important problem in the fields of transportation, distribution and logistics. Several variations and specializations of the vehicle routing

Problem exist like VRP problems having time windows within which the deliveries must be made and VRP with limited carrying capacity of vehicles. Clustering is a Machine Learning technique that involves the grouping of data points. Given a set of data points, we can use a clustering algorithm to classify each data point into a specific group. Data points that are in the same group should have similar properties. And/or features, while data points in different groups should have highly dissimilar properties and/or features. K-Means clustering can be used to get a combination of cities with respective to the centroid. Village's gets cluster as a group based upon the centroid, customer points will have minimum distance with all the other villages present in the group. XY co-ordinates of customer.

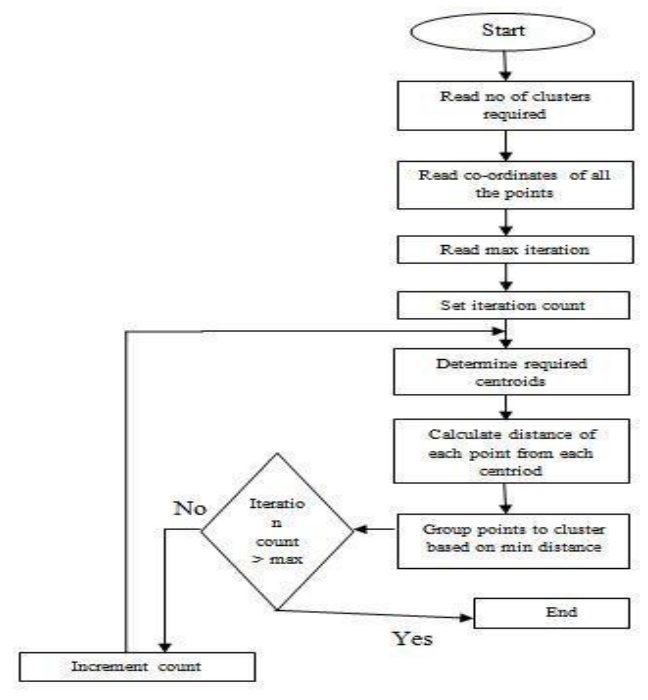

Figure 1.k-means algorithm for clustering

The flow chart of the K-Means Method the clustering can made for 15 cluster, 16 cluster, 17 cluster, 18 cluster reason for going up to 18 , In existing scenario dairy industry uses 19 vehicles, hence to reduce the number of vehicles clustering limited as 18 . Each cluster can have few or many villages in the group, these each cluster mean that one vehicle can send to the cluster with minimum distance, and should not exceed vehicle capacity. After clustering routing is done using LINGO solver. LINGO is a comprehensive tool designed to make building and solving Linear, Nonlinear (convex \& nonconvex/Global), Quadratic, Quadratically Constrained, Second Order Cone, SemiDefinite, Stochastic, and Integer optimization models faster, easier and more efficient. LINGO provides a completely integrated package that includes a powerful language for expressing optimization models, a full featured environment for building and editing problems. LINGO will help you cut your development time. It lets you formulate your linear, nonlinear and integer problems quickly in a highly readable form. Models are easier to build, easier to understand, and, therefore, easier to maintain. LINGO can exploit multiple CPU cores for faster model generation. - LINGO is available with a comprehensive set of fast, built-in solvers for Linear, Nonlinear (convex \& nonconvex/Global), and Quadratic, Quadratically Constrained, Second Order Cone, Stochastic, and Integer optimization. 


\section{RESULT INTERPRETATION}

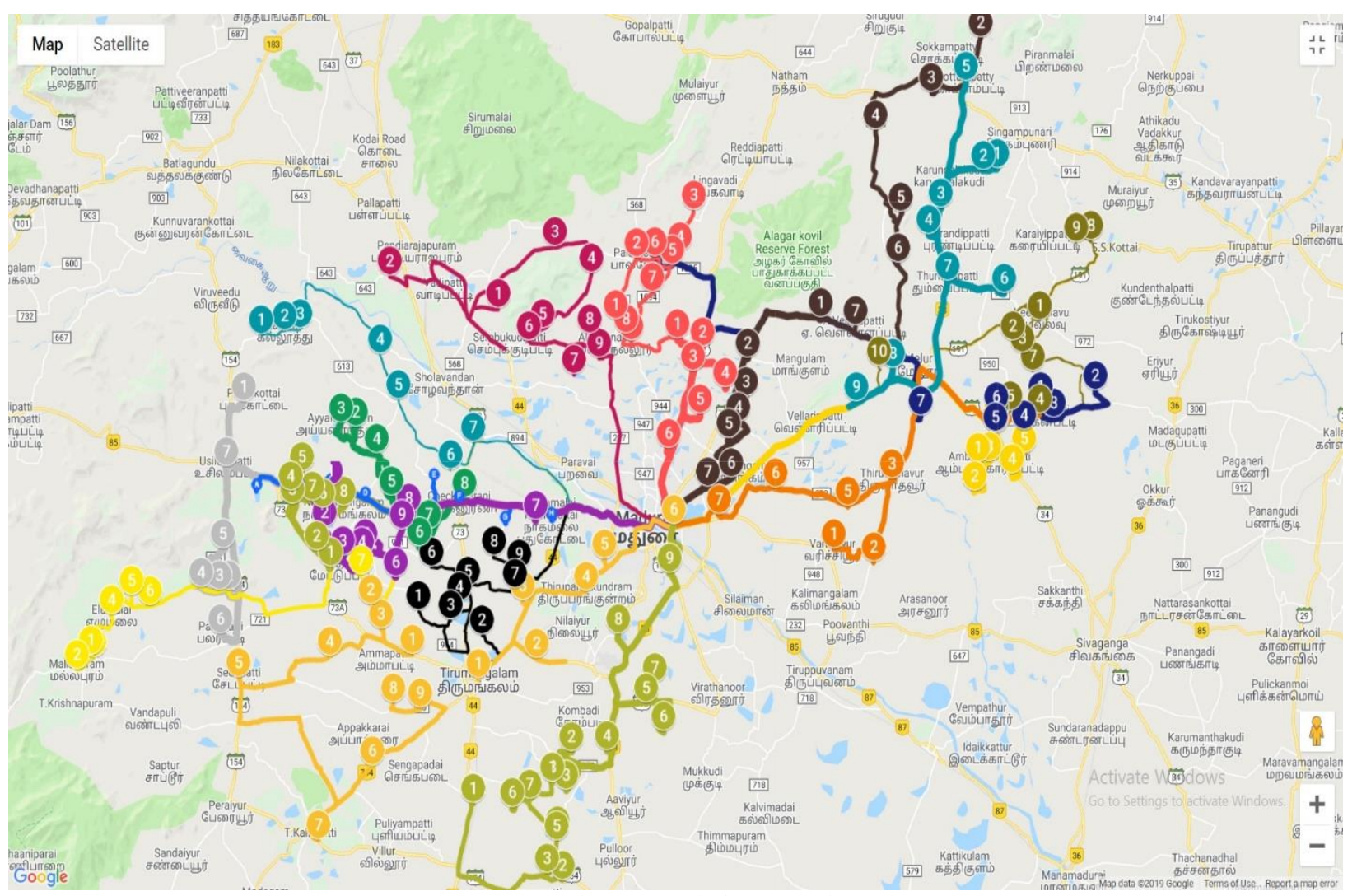

Figure 2 Map before Clustering

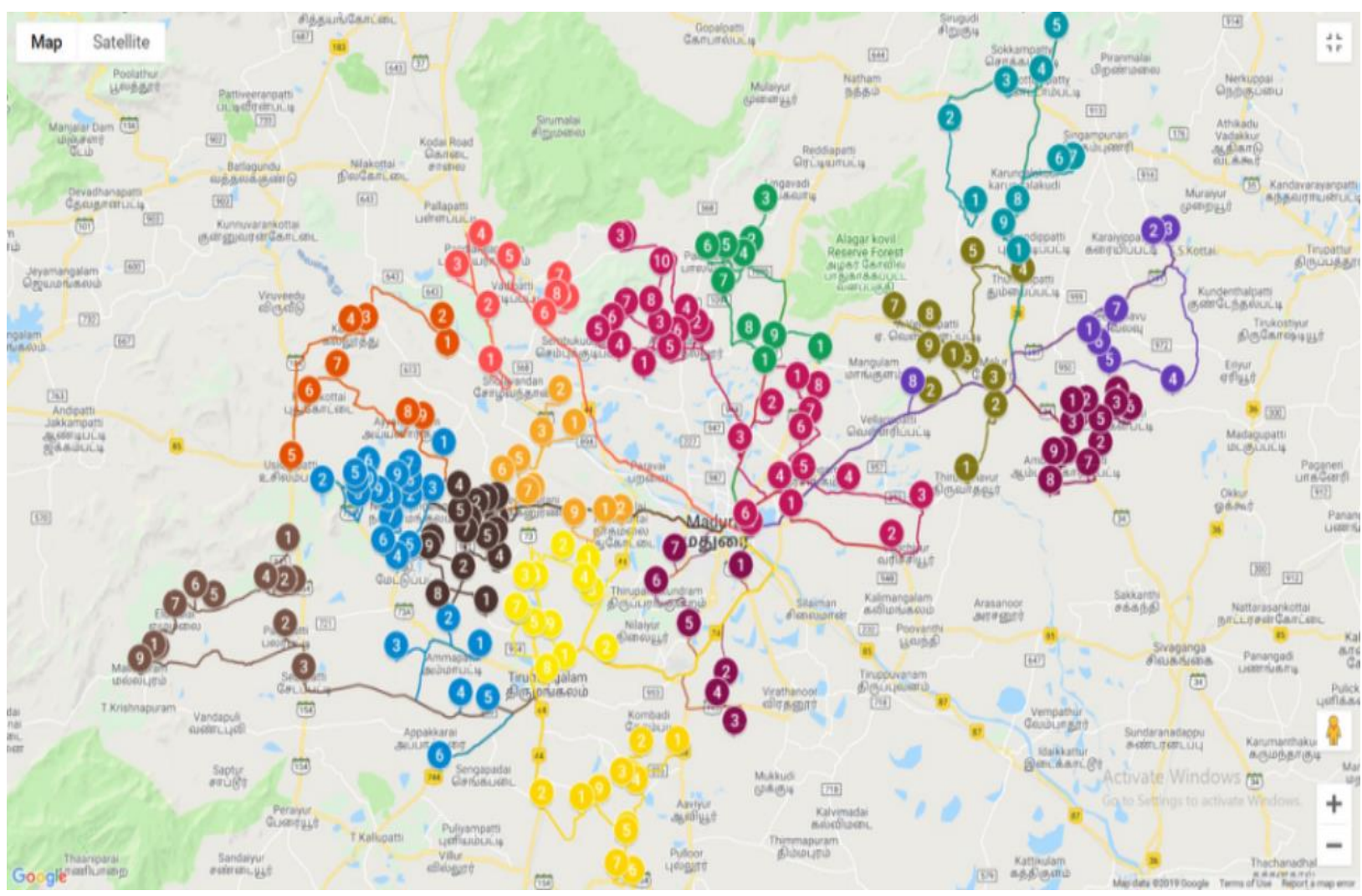

Figure 3 Map after Clustering 


\begin{tabular}{|l|l|l|}
\hline S.NO & \multicolumn{1}{|c|}{ ROUTING OF VEHICLE } & Distance travelled (km) \\
\hline 1 & $\begin{array}{l}\text { V56-V184-V123-V23-V185-V22-V202-V26-V104-V27-V25-V24-V20-V17-V21-V16- } \\
\text { V19-V18-V57-DEPOT }\end{array}$ & 102.50 \\
\hline 2 & V195-V194-V116-V187-V115-V28-V29-V108-V30-V61-V31-DEPOT & 55.00 \\
\hline 3 & $\begin{array}{l}\text { V147-V173-V153-V165-V127-V148-V151-V150-V144-V142-V141-V143-V145- } \\
\text { V172-V146-DEPOT }\end{array}$ & 77.00 \\
\hline 4 & V113-V181-V112-V111-V110-V117-V180-V103-V102-V114-DEPOT & 91.00 \\
\hline 5 & V126-V154-V179-V44-V6-V45-V8-V7-V178-V170-V46-DEPOT & 87.00 \\
\hline 6 & V101-V99-V98-V97-V100-V92-V93-DEPOT & 51.00 \\
\hline 7 & V81-V83-V88-V86-V87-V84-DEPOT & 79.000 \\
\hline 8 & V89-V55-V209-V51-V208-V49-V207-V53-V48-V210-V90-V91-V54-DEPOT & 84.6000 \\
\hline 9 & $\begin{array}{l}\text { V204-V62-V203-V105-V177-V63-V174-V82-V15-V58-V47-V60-V59-V52-V106- } \\
\text { V175-V107-DEPOT }\end{array}$ & 84.0000 \\
\hline 10 & V5-V4-V3-V1-V2-V39-V38-V40-V41-V183-DEPOT & 103.5000 \\
\hline 11 & $\begin{array}{l}\text { V70-V138-V71-V200-V68-V67-V206-V199-V198-V69-V66-V196-V131-V72-V201- } \\
\text { V139-DEPOT }\end{array}$ & 69.80000 \\
\hline 12 & V120-V13-V10-V11-V12-V85-V14-V9-DEPOT & 62.00000 \\
\hline 13 & V32-V134-V133-V135-V136-V132-V137-V140-V156-V157-DEPOT & 49.00000 \\
\hline 14 & V188-V189-V65-V190-V191-V193-V192-V197-V64-DEPOT & 69.000 \\
\hline 15 & V96-V94-V80-V95-V77-V74-V75-V76-V79-V78-V73-DEPOT & 67.00000 \\
\hline 16 & V162-V169-V168-V149-V167-V163-V161-V43-DEPOT & 87.7000 \\
\hline 17 & $\begin{array}{l}\text { V130-V125-V128-V124-V129-V36-V35-V34-V33-V158-V159-V160-V37-V182- } \\
\text { DEPOT }\end{array}$ & 91.40000 \\
\hline
\end{tabular}

Table 1 Lingo Solver Result

\begin{tabular}{|l|l|l|l|l|l|}
\hline S.no & $\begin{array}{l}\text { Combination of } \\
\text { Procurement } \\
\text { points }\end{array}$ & $\begin{array}{l}\text { Total } \\
\text { transportation cost } \\
\text { (Rs) }\end{array}$ & $\begin{array}{l}\text { Number of } \\
\text { vechicles used }\end{array}$ & $\begin{array}{l}\text { Cost reduction per } \\
\text { shift (Rs) }\end{array}$ & $\begin{array}{l}\text { Cost minimization } \\
\text { per month (Rs) }\end{array}$ \\
\hline 1 & $\begin{array}{l}\text { Existing } \\
\text { transportation } \\
\text { cost }\end{array}$ & 38,488 & 19 & - & - \\
\hline 2 & $\begin{array}{l}\text { using k-means } \\
\text { clustering } \\
\text { combination }\end{array}$ & 35,323 & 17 & 3,166 & $1,89,960$ \\
\hline
\end{tabular}

Table 2 Optimization Result

\begin{tabular}{|l|l|l|l|l|l|l|}
\hline CLUSTER & $\begin{array}{l}\text { VEHICLE } \\
\text { TYPE }\end{array}$ & $\begin{array}{l}\text { ACCUMLATED } \\
\text { CAPACITY(NO.OF } \\
\text { TANKS) }\end{array}$ & $\begin{array}{l}\text { ROUTING } \\
\text { DISTANCE } \\
(\mathrm{km})\end{array}$ & $\begin{array}{l}\text { DISTANCE } \\
\text { TRAVEL } \\
\text { Km) }\end{array}$ & $\begin{array}{l}\text { COST PER } \\
\text { Km }\end{array}$ & $\begin{array}{l}\text { TRANSPORTATION } \\
\text { COST (Rs) }\end{array}$ \\
\hline 1 & 709 & 118 & 102.5 & 205 & 14.5 & 2972.5 \\
\hline 2 & 407 & 78 & 55 & 110 & 13 & 1430 \\
\hline 3 & 709 & 129 & 77 & 154 & 14.5 & 2233 \\
\hline 5 & 709 & 124 & 91 & 182 & 14.5 & 2639 \\
\hline 6 & 407 & 74 & 87 & 174 & 13 & 2262 \\
\hline 7 & 407 & 66 & 51 & 102 & 13 & 1326 \\
\hline 8 & 407 & 67 & 79 & 158 & 13 & 2054 \\
\hline 9 & 707 & 75 & 84.6 & 169.2 & 13 & 2199.6 \\
\hline 10 & 407 & 75 & 84 & 168 & 14.5 & 2436 \\
\hline
\end{tabular}




\begin{tabular}{|l|l|l|l|l|l|l|}
\hline 11 & 407 & 77 & 69.8 & 139.6 & 13 & 1814.8 \\
\hline 12 & 709 & 119 & 62 & 124 & 14.5 & 1798 \\
\hline 13 & 407 & 76 & 49 & 98 & 13 & 1274 \\
\hline 14 & 407 & 75 & 69 & 138 & 13 & 1794 \\
\hline 15 & 407 & 77 & 67 & 134 & 13 & 1742 \\
\hline 16 & 407 & 74 & 87.7 & 175.4 & 13 & 2280.2 \\
\hline 17 & 407 & 77 & 91.4 & 182.8 & 13 & 2376.4 \\
\hline
\end{tabular}

Table 4 Clustered Result

Total distance travelled by the trucks per shift (Proposal $)=2621 \mathrm{~km}$

Total transportation cost for the trucks per shift(Proposal) $=$ Rs.35,323

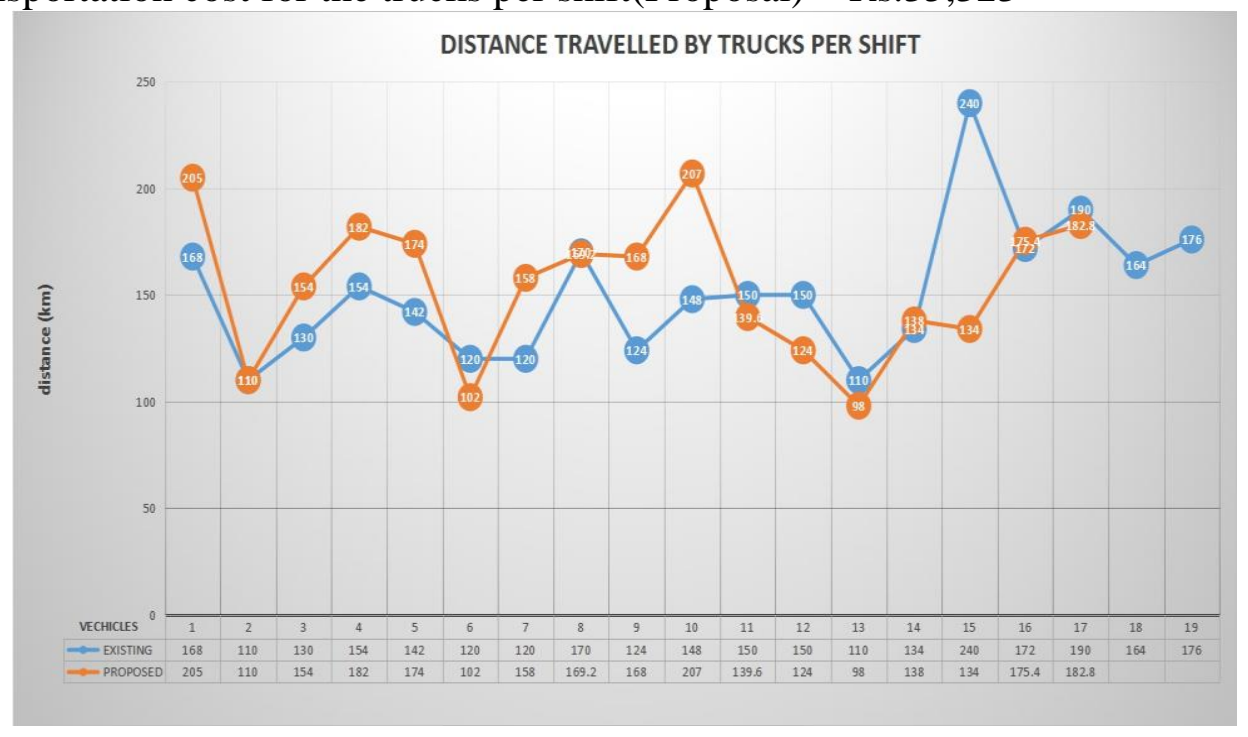

Figure 4 Distance Travelled by Trucks per Shift

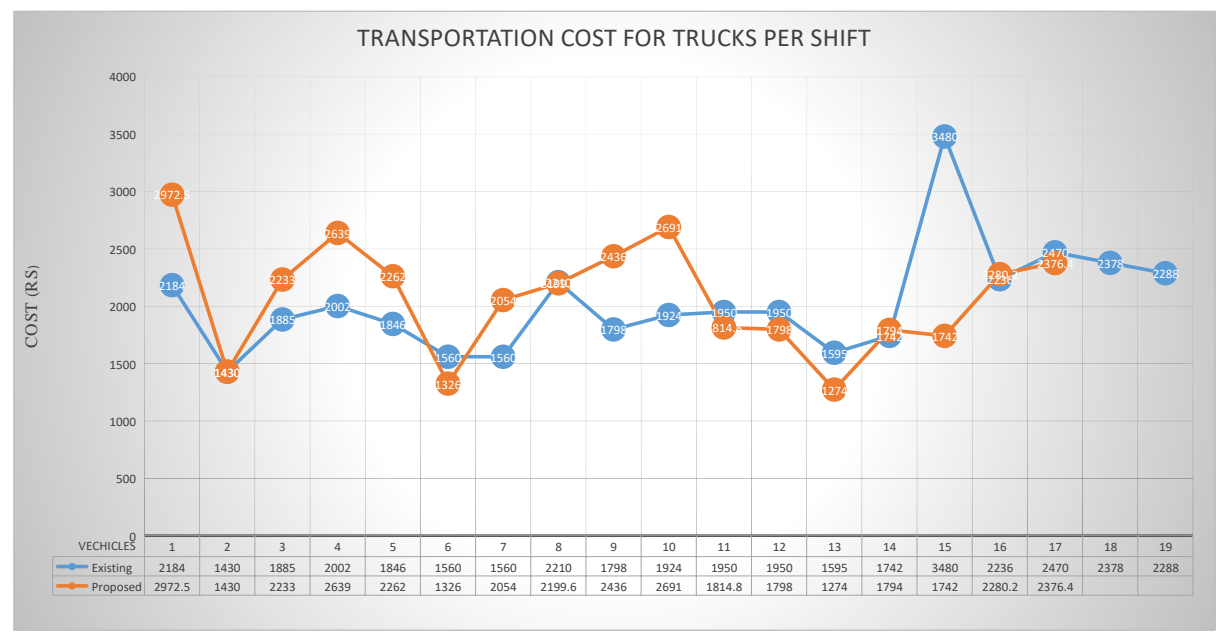

Figure 5 Transportation Cost for Trucks per Shift 


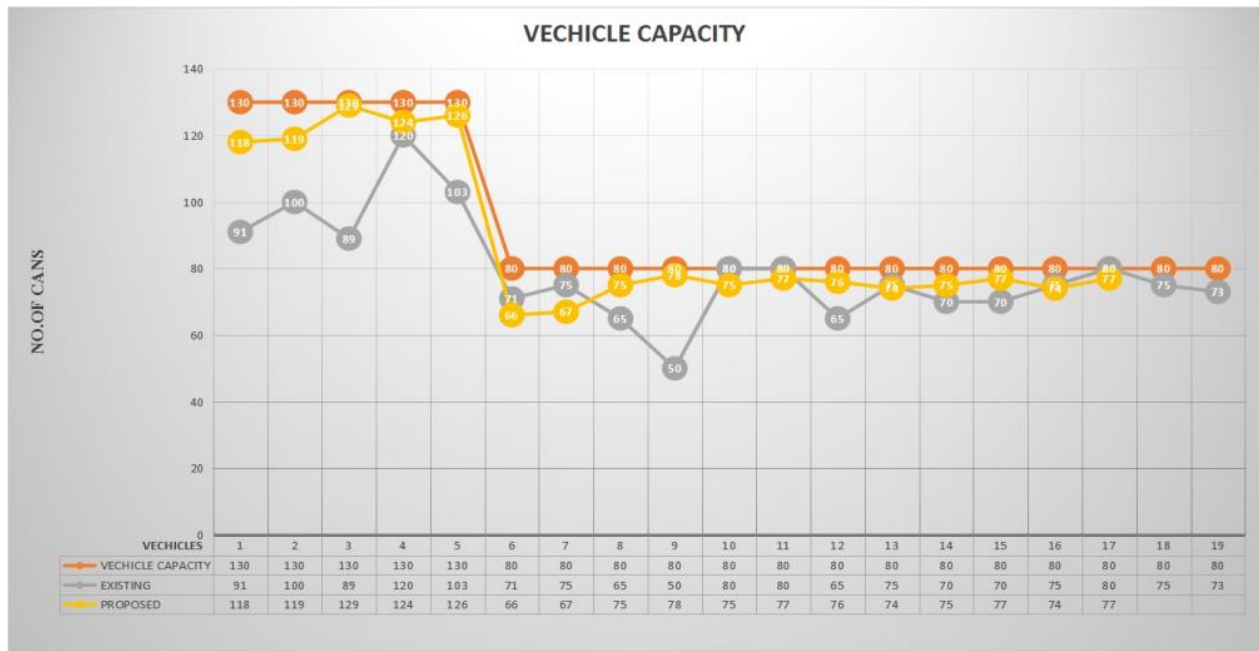

Figure 7 Vehicle Capacity

TOTAL DISTANCE TRAVELLED BY TRUCKS PER $\operatorname{SHIFT}(\mathrm{Km})$

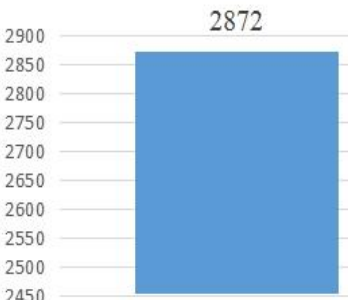

EXISTING

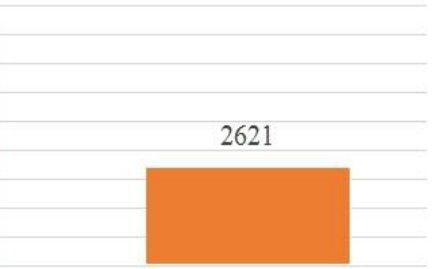

PROPOSED
— EXISTING — PROPOSED

Figure 8 Total Distance Travelled by Trucks per Shift (existing vs proposal)

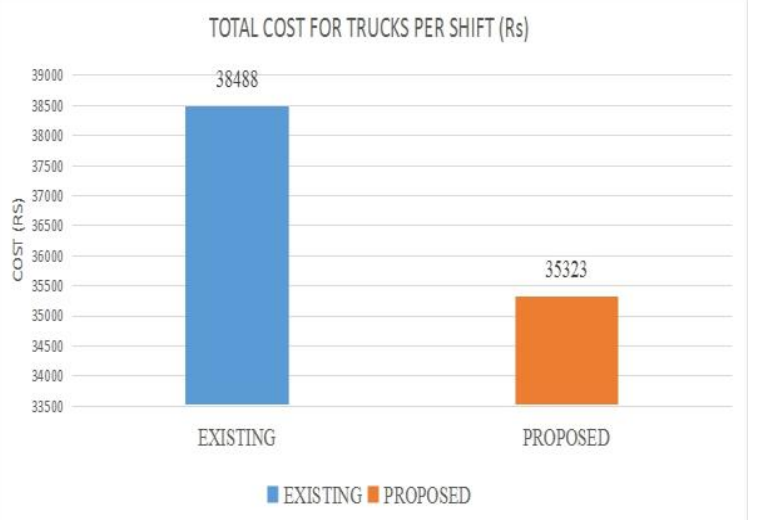

Figure 9 Total Cost for Trucks per Shift (existing vs proposal)

\section{CONCLUSION}

The project aims to provide a approach for reductions in the service distance travelled and also the number of vehicles employed for the task and also utilizing the maximum capacity of vehicle. The task was performed using k-means clustering and lingo solver to obtain optimum result. From the results and it is concluded that, travelling distance between the milk pick up points has been minimized and number of vehicles used for procurement also reduced thereby transportation cost reduced considerably .Cost savings is Rs.3,166 and Number of vehicles reduced from 19 to 17 . Thus, the obtained result substantiates the effectiveness of the application of the proposed method. Thus this approach is enables to attain optimum operating cost while the plant go for further establishment.

\section{REFERENCES}

[1] Ananad Subramanian,Igor Machado,Luiz Satoru Ochic,A hybrid algorithm for a class of vehicle routing problems with time window-Computers \& Operations Research,Volume 40, Issue 10, October 2013, Pages 2519-2531

[2] ÇağriSel,Bloemhof-Ruwaard, Planning scheduling of the make-and-pack dairy production under lifetime uncertaintyApplied Mathematical Modelling,Volume 51, November 2017, Pages 129-144

[3] Clement Scaria,Jenson Joseph Optimization of Transportation Route for a Milk Dairy International-Journal of Engineer Research \& technology(IJERT),ISSN:22780181, IJERTV31S0577,Vol.3 Issue 11,November-2014

[4] Harisri.M.Thulasi,A.K.Agrawal,S.K.Sharma,Vechicle routing Approach for Improvement in the Supply Chain of Milk Industry-Journal of Basic and Applied Engineering ResearchISSN: 2350-0077; e-ISSN: 2350-0255; Volume 3, Issue 8; April-June, 2016, pp. 701-704.

[5] KhanittaRuangwittayanusorn,DoungnapaPromket,AnutChanti atikul,Monitoring the Hygiene of Raw Milk from Farms to Milk Retailers,-Agriculture and Agricultural Science Procedia, Volume 11, 2016, Pages 95-99.

[6] Mishra, P.K. and Raja Shekhar, B. 'Evaluating supply chain risk in Indian dairy industry:a case study', Int. J. Decision Sciences, Risk and Management, Vol. 4,Nos. 1/2, pp.77-91.

[7] Muthu karthikeyan, Dr. M. Elango,Minimization of Transportation Cost in Courier Service Industry, International Journal of Innovative Research in Science, Engineering and Technology, Volume 3, Special Issue 3, March 2014

[8] Roberto Baldacci , Aristide Mengzi , Roberto Roberti, Recent exact algorithms for solving the vehicle routing problem under capacity and time window constraints-European Journal of Operational Research,Volume 218, Issue 1, 1 April 2012, Pages $1-6$

[9] SubburajaT.RameshBabu, SureshSubramonia, A Study on Strengthening the Operational Efficiency of Dairy Supply Chain in Tamilnadu, India- Procedia - Social and Behavioral Sciences, Volume 189, 15 May 2015, Pages 285-291

[10] Allan Larsen, Oli B. G. Madsen, Marius M. Solomon, „The A Priori Dynamic Traveling Salesman Problem with Time Windows"e. Transportation Science 38(4):459-472 